\title{
Predictors of switching antipsychotic medications in the treatment of schizophrenia
}

\author{
Allen W Nyhuis, Douglas E Faries, Haya Ascher-Svanum, Virginia L Stauffer, Bruce J Kinon
}

\begin{abstract}
Background: To identify patient characteristics and early changes in patients' clinical status that best predict subsequent switching of antipsychotic agents in the long-term treatment of schizophrenia.

Methods: This post-hoc analysis used data from a one-year randomized, open-label, multisite study of antipsychotics in the treatment of schizophrenia. The study protocol permitted switching of antipsychotics when clinically warranted after the first eight weeks. Baseline patient characteristics were assessed using standard psychiatric measures and reviews of medical records. The prediction model included baseline sociodemographics, comorbid psychiatric and non-psychiatric conditions, body weight, clinical and functional variables, as well as change scores on standard efficacy and tolerability measures during the first two weeks of treatment. Cox proportional hazards modeling was used to identify the best predictors of switching from the initially assigned antipsychotic medication.
\end{abstract}

Results: About one-third of patients $(29.5 \%, 191 / 648)$ switched antipsychotics before the end of the one-year study. There were six variables identified as the best predictors of switching: lack of antipsychotic use in the prior year, pre-existing depression, female gender, lack of substance use disorder, worsening of akathisia (as measured by the Barnes Akathisia Scale), and worsening of symptoms of depression/anxiety (subscale score on the Positive and Negative Syndrome Scale) during the first two weeks of antipsychotic therapy.

Conclusions: Switching antipsychotics appears to be prevalent in the naturalistic treatment of schizophrenia and can be predicted by a small and distinct set of variables. Interestingly, worsening of anxiety and depressive symptoms and of akathisia following two weeks of treatment were among the more robust predictors of subsequent switching of antipsychotics.

\section{Background}

Antipsychotic medications are mainstays in the clinical management of schizophrenia. Although generally effective in ameliorating core manifestations of the disease, some patients experience only suboptimal responses or are intolerant of the medication. This may include insufficient improvement or even worsening of symptoms, as well as a variety of treatment-related adverse events $[1,2]$. Under such clinical circumstances, a change (i.e., switch) in the antipsychotic medication regimen is warranted, representing a rational rescue treatment option in the hope that the switch will result in better treatment outcomes for the patient [3-10].

\footnotetext{
* Correspondence: haya@illy.com

Eli Lilly and Company, Indianapolis, IN USA
}

Reasons for antipsychotic switching or discontinuation are varied $[2,11]$; however, data from naturalistic clinical settings on the frequency of antipsychotic switching, as well as the timing and predictors of such medication changes, are limited. Previous studies evaluating predictors of switching $[12,13]$ assessed a relatively narrow range of variables and did so for patients who may not be representative of those treated in usual outpatient care settings. Furthermore, previous research assessed predictors of medication switching at discrete time points $[12,13]$, thus providing a time-limited context for this dynamic treatment practice. For example, the study by Weinmann and colleagues [13] evaluated switching from first-generation to second-generation antipsychotics among inpatients with schizophrenia. However, hospitalizations are often triggered by poor treatment responses or nonadherence with the previous antipsychotic regimen 
and thus inherently necessitate medication alterations (switches). Furthermore, inpatient data are not representative of outpatient clinical practice settings. Another study, by Sernyak and colleagues [12], used an administrative claims database to identify predictors of medication switching among patients with schizophrenia treated at the Veterans Health Administration. Independent variables included information about service utilization, sociodemographic, and a few clinical variables. The study concluded that high levels of outpatient and inpatient service use were the most powerful predictors of switching, while sociodemographic, institutional, diagnostic, and functional measures were also predictive in some cases.

The purpose of our study was to expand current research and identify individual patient characteristics that best predict switching of antipsychotic medications among predominately outpatients treated for schizophrenia and related disorders. This study is focused on patients who switch antipsychotic medication (switchers), the ones who constitute the pool of patients who remain engaged in treatment, for whom the clinicians have to consider different treatment choices to replace the current therapy. Unlike patients who drop out of treatment (discontinuers), the switchers show interest in further treatment and are available for initiation of alternative treatment options. Our previous research [14] has suggested that although treatment discontinuation for any cause (switch or discontinuation) is an important proxy measure of a medication's effectiveness, the differences between antipsychotic medications on this proxy measure may be primarily driven by switching of the medication (when switching is a study option) rather than discontinuation. Our prior research [15] has also helped to show that in the treatment of patients with schizophrenia, switching antipsychotics may be a meaningful marker of treatment failure, considering its significant association with more frequent and more rapid use of acute care services (hospitalization and crisis services) compared with persons remaining on their initial treatment.

Therefore, to identify individual patient characteristics that best predict switching of antipsychotic medications in the treatment of schizophrenia, we conducted a posthoc analysis of a one-year randomized, open-label, multisite cost-effectiveness study of antipsychotic medications in the treatment of schizophrenia in the United States. Consistent with the parent study protocol, switching of the initially randomized antipsychotic was permitted if clinically warranted [16-18]. The objectives of the current study were to assess the frequency of antipsychotic switching, the time to switching, and the patient and treatment characteristics that best predict subsequent switching of antipsychotics over a one-year period. We used numerous independent variables to reflect baseline patient sociodemographic and clinical characteristics, as well as early clinical changes observed within the first two weeks of antipsychotic therapy.

\section{Methods}

\section{Data source}

We used data from a Lilly-sponsored, randomized, open-label, one-year, multicenter, cost-effectiveness study of antipsychotics in the treatment of schizophrenia (HGGD). This study compared the cost-effectiveness of initial treatment with olanzapine versus a "fail-first" on typical antipsychotics (then olanzapine if indicated) and versus initial treatment with risperidone. The study was conducted at 21 sites in 15 states from May 1998 through September 2002, and its primary findings have been published [17]. Briefly, the study found that requiring failure on less expensive antipsychotics before use of olanzapine did not result in total cost savings, despite significantly higher antipsychotic costs with olanzapine.

The study included patients who were deemed by their physicians to warrant a change in their antipsychotic medication, using broad eligibility criteria: patients aged 18 years or older with a DSM-IV diagnosis of schizophrenia, schizoaffective, or schizophreniform disorder, provided they scored $\geq 18$ on the Brief Psychiatric Rating Scale (BPRS) [19]. No patient was excluded because of comorbid substance use disorders or other psychiatric or medical comorbidities, unless the condition was severe. Almost all enrollees were outpatients (95\%).

At study initiation, patients were randomized to one of three open-label treatment groups: olanzapine $(n=$ $229)$; risperidone $(\mathrm{n}=221)$; or first-generation antipsychotic of physician's choice $(n=214)$. Patients remained on their initially assigned medication for at least eight weeks, after which, if clinically warranted per clinicians' judgment, patients' regimens could be changed to a different antipsychotic agent. Patients were assessed at baseline and at five predetermined post-baseline visits (2 weeks; $2,5,8$, and 12 months post-baseline), regardless of the time of medication switch. The protocol and consent procedures were approved by institutional review boards, and after being provided with a complete description of the study, signed consent forms were obtained from patients prior to participation.

\section{Assessments and predictor variables}

A wide range of independent variables was evaluated in patients who switched antipsychotic treatment compared with their counterparts who completed the study without a switch.

Baseline sociodemographic variables included age, gender, race/ethnicity, educational attainment, marital status, employment, and insurance status. Baseline 
clinical variables included symptom severity, quality of life, functional status, safety and tolerability, hospitalizations and emergency services in the year prior to enrollment, illness duration, use of antipsychotic and switching of antipsychotics in the prior year, prior adherence with antipsychotics defined as the medication possession ratio (MPR, the proportion of days with any antipsychotic during the one-year prior to enrollment), pre-existing comorbid psychiatric and non-psychiatric conditions (assessed at enrollment, including depression and insomnia), total number of pre-existing comorbid conditions of any type, past incarcerations, and past suicide attempts.

To help identify predictor variables that emerge during the early phase of treatment ("early on-treatment variables"), a wide range of variables was measured at baseline and again at two weeks post-baseline to compute a two-week change score. These "on-treatment variables" reflected measures of symptomatology, quality of life, functional status, safety, and tolerability. Changes occurring during the first two weeks of treatment were used based on previous research showing that most improvements are observed during the first two weeks of treatment [20] and that early non-response to medication is a robust predictor of subsequent non-response to the same antipsychotic medication [21-24].

Symptomatology was assessed using the Positive and Negative Syndrome Scale (PANSS) [25] total score and the five PANSS factor subscales [26]. Quality of life was assessed using the 17 subscales (nine subjective, eight objective) of the Lehman Quality of Life Interview [27]. Functional status was measured with the eight subscale scores and two composite scores of the MOS 36-item short form health survey (SF-36) [28]. Global assessment of functioning (GAF) was also included [29].

Safety and tolerability (at baseline and again following two weeks of treatment) was determined using clinicianrated scales for akathisia [30] and extrapyramidal symptoms [31]. Baseline body weight and treatment-emergent weight gain during the first two weeks of treatment were assessed. The study did not include measures of metabolic parameters (other than weight) or prolactin levels.

\section{Statistical analysis}

Data from patients who discontinued their initially assigned antipsychotic and were switched to another antipsychotic within 14 days of medication discontinuation (switchers) were compared with those who completed the one-year study on their randomized medication (nonswitchers). Patients who discontinued the study early (dropouts) without a switch prior to study discontinuation were not included in the present analysis. The switcher group was aggregated across the three medication treatment groups, as was the nonswitcher group. This was done since the assessed reasons for switching (i.e., patient request, lack of efficacy, medication intolerability, other) did not significantly differ among the three treatment groups, although the switching rate was significantly lower for patients randomized to olanzapine (14\%) compared to a typical antipsychotic $(53 \%, \mathrm{p}<.001)$ and to risperidone $(31 \%, \mathrm{p}<$ .001) [17].

Chi-square, Fisher's exact, Wilcoxon rank-sum, and independent $t$ tests were used to conduct univariate comparisons of all potential predictor variables between switchers and nonswitchers. The relationship between each potential predictor variable and time to switching was assessed univariately using Cox proportional hazards regression. Time to switching was defined as remaining in the study on the initially assigned medication without switching. If a patient's regimen was not switched over the one-year study period, the survival time (time to switching) was censored either at study completion or when the patient prematurely discontinued the study.

Predictor variables identified from the above analyses (with $\mathrm{p}<.05$ from either the univariate survival analysis or the comparisons between switcher and nonswitcher groups) were used as initial variables in fitting a predictive model using Cox proportional hazards, with the outcome variable being time-to-switch. Using this initial model as a starting point, the final predictor variables were determined by utilizing a manual stepwise procedure (with $\mathrm{p}<.05$ as the criterion for variables to either enter or stay in the model), using all of the potential predictor variables (including variables not in the initial model). Once the final predictors were determined, all two-way interactions involving the final predictor variables were tested for inclusion in the final model. Significance was defined a priori at a two-tailed alpha $\leq .05$.

As a sensitivity analysis, the final predictive model was refit on only the set of patients who did not continue on the same treatment at randomization as they were already taking pre-baseline. This was done to address the possibility that continuing on the same treatment might be predictive of earlier or later switching.

To illustrate the associations between each of the final predictor variables and time to switching, a graph of the Kaplan-Meier estimated survival distribution was produced in a univariate fashion separately for each predictor variable.

\section{Results}

Of 664 patients enrolled in the parent study, 16 (2.4\%) either failed to or delayed taking their randomized medication, leaving an analysis dataset of 648 patients (Figure 1). A total of 304 (46.9\%) of the 648 patients 


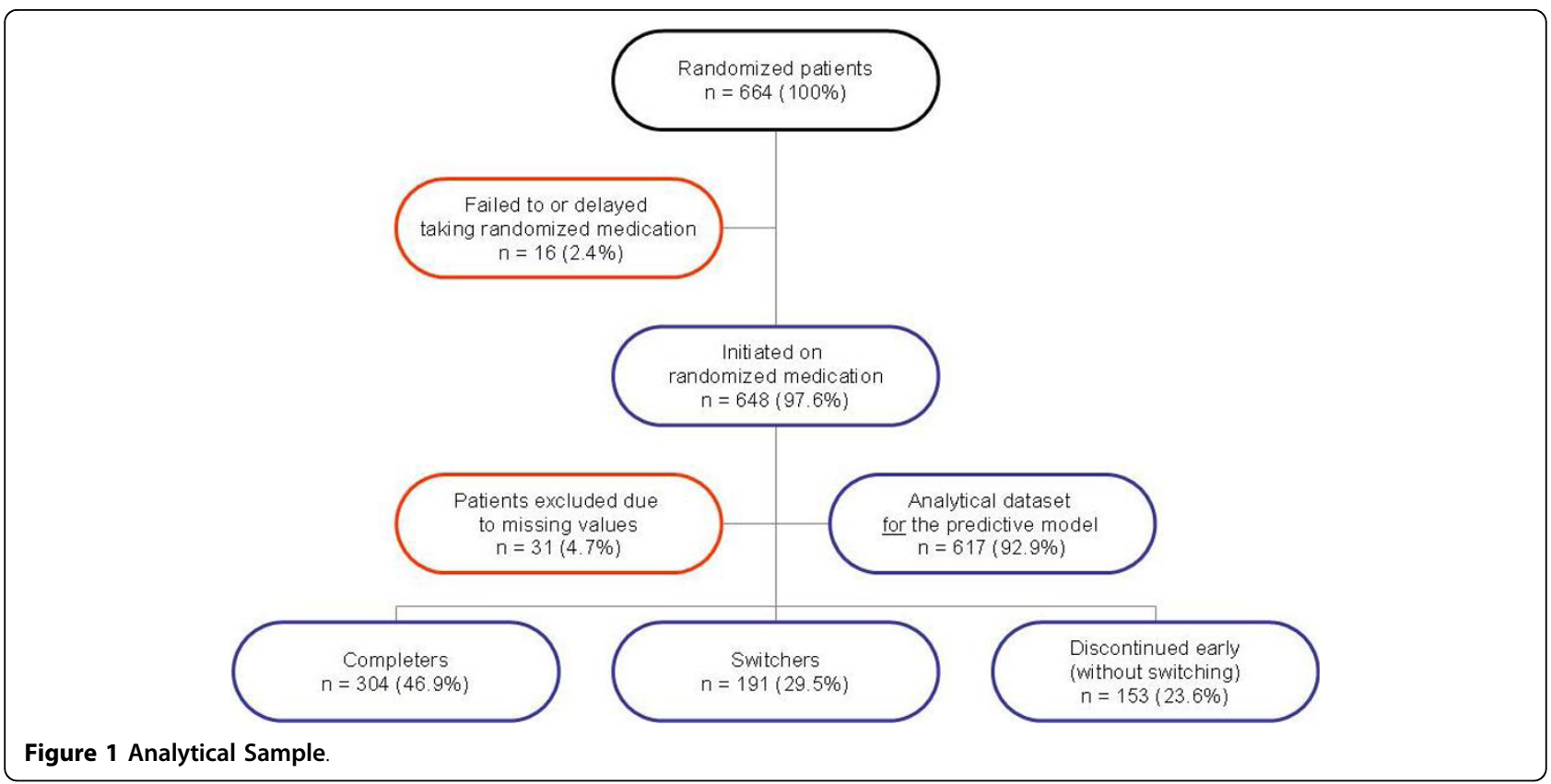

completed the one-year study on the randomly assigned medication (i.e., nonswitchers), whereas 191 (29.5\%) switched to a different antipsychotic (i.e., switchers). The remaining 153 patients (23.6\%) discontinued participation in the study without switching to a new medication prior to dropout. These "early discontinuers" had a mean age of 41.3 , with $70 \%$ of them Male, $49 \%$ Caucasian, 53\% Single/Never Married, and their mean Total PANSS score was 88.3 . Only $14 \%$ of this group were Employed, but 55\% had a Substance Abuse diagnosis in the past year, and $60 \%$ of them have been Incarcerated. Among medication switchers, the reasons for the switching were noted as patient decision (34.6\%), lack of medication efficacy (27.7\%), adverse event (22.5\%), and other or unknown reasons (15.2\%). Results of the univariate analyses revealed several variables that were significantly $(\mathrm{p}<.05)$ associated with switching: female gender; no previous antipsychotic treatment in the year before study initiation; no current or lifetime diagnosis of substance use disorder; pre-existing insomnia; and early (within two weeks post-baseline) worsening of depressive symptoms per scores on the depression/anxiety subscale of the PANSS (Table 1). Baseline body weight and change in weight during the first two weeks of treatment did not predict switching in this study. Similarly, quality of life, functional variables, employment, insurance status, and adherence level in prior year (per MPR) were not predictive of switching or earlier switching.

According to the multivariate regression model, six variables were found to significantly predict $(\mathrm{p}<.05)$ antipsychotic switching: four baseline patient characteristics and two early treatment variables (Table 2). The four baseline characteristics were female gender, pre-existing depression, lack of antipsychotic medication use in the year prior to the study, and lack of substance use disorder. The two early treatment variables were worsening of anxiety/depression symptoms (per PANSS subscale score) and worsening of akathisia (per Barnes Akathisia objective score) in the first two weeks of treatment. According to the hazard ratios, women were $37.6 \%$ more likely to switch earlier than their male counterparts, and patients with pre-existing depression were $48.4 \%$ more likely to switch before similar patients without pre-existing depression. Alternatively, participants less likely to switch medications included those who were treated with any antipsychotic in the year before the study (38.3\% less likely) and those diagnosed with substance use disorder (26.9\% less likely).

There were two early treatment variables significantly predictive of an increased likelihood of earlier switching, one associated with medication efficacy and the other with medication intolerability. These variables were an increase (worsening) of the PANSS depression/anxiety subscale score and an increase (worsening) of the Barnes Akathisia objective score (Table 2) in the first two weeks of treatment. According to the hazard ratios, for every 1point increase on the PANSS depression/anxiety subscale score, patients had a 5.1\% higher likelihood of switching sooner than those without such changes in scores. A 2point increase in the PANSS depression/anxiety subscale score was associated with a $10.5 \%$ higher likelihood of switching earlier, whereas a 1-point decrease (improvement) reduced the likelihood of an earlier switch by $4.9 \%$. 
Table 1 Baseline Characteristics and Selected Univariate Predictors of Switching

\begin{tabular}{|c|c|c|c|c|c|}
\hline Variable & $\begin{array}{l}\text { All } \\
\text { patients } \\
(\mathrm{N}=648)\end{array}$ & $\begin{array}{l}\text { Switchers } \\
(\mathrm{n}=191)\end{array}$ & $\begin{array}{l}\text { Completers } \\
(\mathrm{n}=304)\end{array}$ & $\begin{array}{l}\text { p value } \\
\text { (switchers } \\
\text { vs. } \\
\text { completers) }^{1}\end{array}$ & $\begin{array}{l}\text { p value } \\
\text { (univariate } \\
\text { survival } \\
\text { comparison) }^{2}\end{array}$ \\
\hline Age, mean (SD), y & $42.9(12.1)$ & $42.8(12.5)$ & $43.7(11.8)$ & 0.404 & 0.724 \\
\hline Female, n (\%) & $239(37 \%)$ & $87(46 \%)$ & $106(35 \%)$ & 0.018 & 0.013 \\
\hline Caucasian, n (\%) & $352(54 \%)$ & $107(56 \%)$ & $170(56 \%)$ & 0.998 & 0.890 \\
\hline $\begin{array}{l}\text { Currently employed, } \\
\text { n (\%) }\end{array}$ & $122(19 \%)$ & $36(19 \%)$ & $64(21 \%)$ & 0.568 & 0.903 \\
\hline Illness duration, mean (SD), y & $20.6(12.2)$ & $20.6(12.6)$ & $21.3(12.1)$ & 0.577 & 0.981 \\
\hline $\begin{array}{l}\text { Hospitalized, previous year, mo } \\
\text { mean (SD) }\end{array}$ & $0.51(1.53)$ & $0.40(1.25)$ & $0.49(1.54)$ & 0.450 & 0.343 \\
\hline Switch in previous year, n (\%) & $85(13 \%)$ & $23(13 \%)$ & $44(15 \%)$ & 0.588 & 0.650 \\
\hline Any antipsychotic previous year, n (\%) & $579(89 \%)$ & $165(86 \%)$ & $284(93 \%)$ & 0.011 & 0.095 \\
\hline Substance abuse diagnosis, n (\%) & $289(45 \%)$ & $70(37 \%)$ & $135(44 \%)$ & 0.111 & 0.038 \\
\hline Schizoaffective diagnosis, n (\%) & $280(43 \%)$ & $80(42 \%)$ & $130(43 \%)$ & 0.852 & 0.795 \\
\hline Ever attempted suicide, $\mathrm{n}(\%)$ & $235(38 \%)$ & $78(43 \%)$ & $99(34 \%)$ & 0.064 & 0.084 \\
\hline $\begin{array}{l}\text { Ever incarcerated, } \\
\mathrm{n}(\%)\end{array}$ & $284(46 \%)$ & $71(38 \%)$ & $127(43 \%)$ & 0.295 & 0.075 \\
\hline PANSS total score, mean (SD) & $86.8(20.0)$ & $84.5(18.8)$ & $87.4(21.1)$ & 0.120 & 0.102 \\
\hline PANSS Davis, positive symptoms, mean (SD) & $22.3(6.3)$ & $21.9(5.8)$ & $22.1(6.6)$ & 0.796 & 0.545 \\
\hline PANSS Davis, negative symptoms, mean (SD) & $21.3(7.0)$ & $20.4(6.8)$ & $21.9(7.3)$ & 0.026 & 0.043 \\
\hline PANSS Davis, impulsivity/hostility, mean (SD) & $8.9(3.6)$ & $8.9(3.9)$ & $8.9(3.6)$ & 0.990 & 0.675 \\
\hline PANSS Davis, disorganized thought, mean (SD) & $21.2(6.0)$ & $20.7(5.6)$ & $21.6(6.3)$ & 0.096 & 0.085 \\
\hline PANSS Davis, anxiety/depression, mean (SD) & $13.0(4.2)$ & $12.7(4.0)$ & $13.0(4.3)$ & 0.411 & 0.445 \\
\hline SF-36 Physical component score, mean (SD) & $-0.43(1.04)$ & $-0.43(1.05)$ & $-0.42(1.01)$ & 0.963 & 0.803 \\
\hline SF-36 Mental component score, mean (SD) & $-1.08(1.33)$ & $-1.14(1.33)$ & $-0.82(1.28)$ & 0.009 & 0.106 \\
\hline Barnes Akathisia & 0.24 & $0.20(0.53)$ & $0.25(0.62)$ & 0.356 & 0.273 \\
\hline item \#1, objective, mean (SD) & $(0.57)$ & & & & \\
\hline Barnes Akathisia, total score, mean (SD) & $0.99(1.58)$ & $0.96(1.46)$ & $0.95(1.67)$ & 0.954 & 0.813 \\
\hline GAF functioning, current score, mean (SD) & $46.1(12.9)$ & $47.2(13.4)$ & $47.0(13.2)$ & 0.842 & 0.323 \\
\hline Antidepressant Drugs taken (\%) & $297(46 \%)$ & $85(45 \%)$ & $212(46 \%)$ & 0.667 & 0.340 \\
\hline $\begin{array}{l}\text { Anti-Anxiety } \\
\text { Drugs taken (\%) }\end{array}$ & $187(29 \%)$ & $54(28 \%)$ & $133(29 \%)$ & 0.850 & 0.810 \\
\hline $\begin{array}{l}\text { Antiparkinsonian } \\
\text { Drugs taken (\%) }\end{array}$ & $315(49 \%)$ & $93(49 \%)$ & $222(49 \%)$ & 1.000 & 0.453 \\
\hline Patient weight, mean (SD), kg & $86.7(20.7)$ & $86.9(21.2)$ & $87.7(20.4)$ & 0.706 & 0.947 \\
\hline Body mass index, mean (SD) & $29.7(6.8)$ & $30.4(7.1)$ & $29.8(6.9)$ & 0.426 & 0.229 \\
\hline Patient weight change from baseline to 2 weeks, mean (SD), $\mathrm{kg}$ & $+0.8(2.8)$ & $+0.7(3.2)$ & $+0.8(2.4)$ & 0.706 & 0.646 \\
\hline Pre-existing depression, n (\%) & $96(15 \%)$ & $36(19 \%)$ & $39(13 \%)$ & 0.073 & 0.056 \\
\hline Pre-existing insomnia, n (\%) & $66(10 \%)$ & $26(14 \%)$ & $24(8 \%)$ & 0.047 & 0.030 \\
\hline $\begin{array}{l}\text { PANSS Davis anxiety/depression, change from baseline to } 2 \text { weeks, } \\
\text { mean (SD) }\end{array}$ & $-1.42(3.47)$ & $-1.19(3.74)$ & $-1.88(3.36)$ & 0.041 & 0.093 \\
\hline $\begin{array}{l}\text { Barnes Akathisia objective score, change from baseline to } 2 \text { weeks, } \\
\text { mean (SD) }\end{array}$ & $-0.04(0.59)$ & $\begin{array}{l}+0.02 \\
(0.62)\end{array}$ & $-0.05(0.57)$ & 0.193 & 0.058 \\
\hline
\end{tabular}

Abbreviations: PANSS, positive and negative syndrome scale; SD, standard deviation; SF-36, Medical Outcomes Study 36-item short form health survey; GAF, global assessment of functioning scale.

${ }^{1}$ Univariate descriptive statistic comparisons, using unpaired t-tests for numeric data (confirming with Wilcoxon rank-sum test, if non-normality was suspected) or chi-square tests (or Fisher's exact test, for small numbers) for categorical data.

${ }^{2}$ Univariate survival comparisons, using Cox proportional hazards models with only the one single variable. 
Table 2 Proportional Hazards Model of Predictor Variables

\begin{tabular}{|c|c|c|c|}
\hline Variable & $\begin{array}{l}\text { Cox proportional } \\
\text { hazards model } \\
\text { parameter }\end{array}$ & p value & $\begin{array}{l}\text { Hazard ratio } \\
\text { ( } 95 \% \text { confidence } \\
\text { interval) }\end{array}$ \\
\hline Female & +0.3192 & 0.0335 & $1.376(1.025-1.847)$ \\
\hline Any antipsychotic in the previous year & -0.4836 & 0.0262 & $0.617(0.403-0.944)$ \\
\hline Substance abuse diagnosis & -0.3133 & 0.0457 & $0.731(0.538-0.994)$ \\
\hline Pre-existing depression condition & +0.3948 & 0.0344 & $1.484(1.029-2.139)$ \\
\hline PANSS Davis anxiety/depression, change from baseline to 2 weeks & $\begin{array}{l}+0.0498 \\
\text { (per 1-point increase) }\end{array}$ & 0.0320 & $\begin{array}{l}1.051 \text { (1.004-1.100) } \\
\text { (per 1-point increase) }\end{array}$ \\
\hline Barnes akathisia objective score, change from baseline to 2 weeks & $\begin{array}{l}+0.2962 \\
\text { (per 1-point increase) }\end{array}$ & 0.0398 & $\begin{array}{l}1.345 \text { (1.014-1.783) } \\
\text { (per 1-point increase) }\end{array}$ \\
\hline
\end{tabular}

Abbreviations: PANSS, positive and negative syndrome scale.

Furthermore, for every 1-point increase on the Barnes Akathisia objective score, there was a $34.5 \%$ increased likelihood of switching earlier, whereas each 1-point drop was associated with a $25.7 \%$ decreased likelihood of earlier switching as compared with patients whose Barnes Akathisia scores did not drop.

In order to assess how much each predictor has contributed to the model, we determined how much the likelihood ratio changed when each of the six predictor variables was dropped from the model. This provided the rank order from the most to the least significant predictor (smaller number is better, as it indicates a greater effect of dropping that predictor): worsening of PANSS anxiety/depression score during the first two weeks of treatment (likelihood ratio $=19.325$ ); female gender (likelihood ratio $=19.364$ ); lack of antipsychotic medication use in the prior year (likelihood ratio = 19.429); worsening of akathisia in the first two weeks of treatment (likelihood ratio $=19.507$ ); pre-existing depression (likelihood ratio $=19.714$ ); and lack of substance use disorder (likelihood ratio $=20.149$ ). Although Cox proportional hazards regression does not provide a simple statistic (like R-square) to measure the percentage of the total variance in switching explained by the model, the relative "fit" of the model, as assessed by comparing the model with versus without the six predictor variables, indicated a highly significant fit (likelihood ratio $=23.836, \mathrm{p}=.0006$ )

In the survival plots in Figures 2, 3, 4, three of the six significant $(\mathrm{p}<.05)$ predictors of switching (or earlier switching) are illustrated. The figures augment information about the likelihood of switching with information about the time to switching over the one-year study. Of note, worsening in medication efficacy and tolerability within the first two weeks of treatment is clearly significantly associated with earlier switching (Figures 3 and 4).

\section{Discussion}

In this post-hoc analysis of a randomized, open-label study conducted in naturalistic, predominately outpatient settings, nearly one in three (29\%) patients switched before completing one year of therapy with the initially assigned antipsychotic medication. Switching antipsychotics was best predicted by six variables: four baseline and two early on-treatment variables. These included, from most to least statistically significant predictor: worsening of PANSS anxiety/depression score during the first two weeks of treatment, female gender, lack of antipsychotic medication use in the prior year, worsening of akathisia in the first two weeks of treatment, pre-existing depression, and lack of substance use disorder. These six variables were significantly predictive of both switching and of an earlier time to switch. To our knowledge, this is the first study to document patient-level risk factors for earlier switching.

Current findings might help inform clinical decisionmaking in usual practice. Effectively tailoring treatment regimens to patients and optimizing early treatment responses are pivotal challenges in psychiatry. For at least four decades, researchers have sought predictors of treatment outcomes after prescribing antipsychotic medications, with a focus on baseline patient variables (i.e., "moderators") and on-treatment variables (i.e., "mediators") [32]. Findings that early worsening in depressive and anxiety symptoms and in akathisia during the first two weeks of treatment predicted switching or earlier switching support the need for early monitoring of antipsychotic efficacy, tolerability, and safety to optimize treatment outcomes.

Given the observed associations, medication switching (as well as early medication discontinuation for any cause) may constitute a proxy or surrogate marker of treatment failure in many patients. This is important because treatment failure often translates into relapse, which is one of the costliest aspects of schizophrenia management in both economic and human terms [6,33-35]. The sooner such an adverse outcome can be predicted, the sooner treatment can be modified to help avert it.

In addition to early-treatment predictors (mediators), a number of baseline patient characteristics (moderators) 


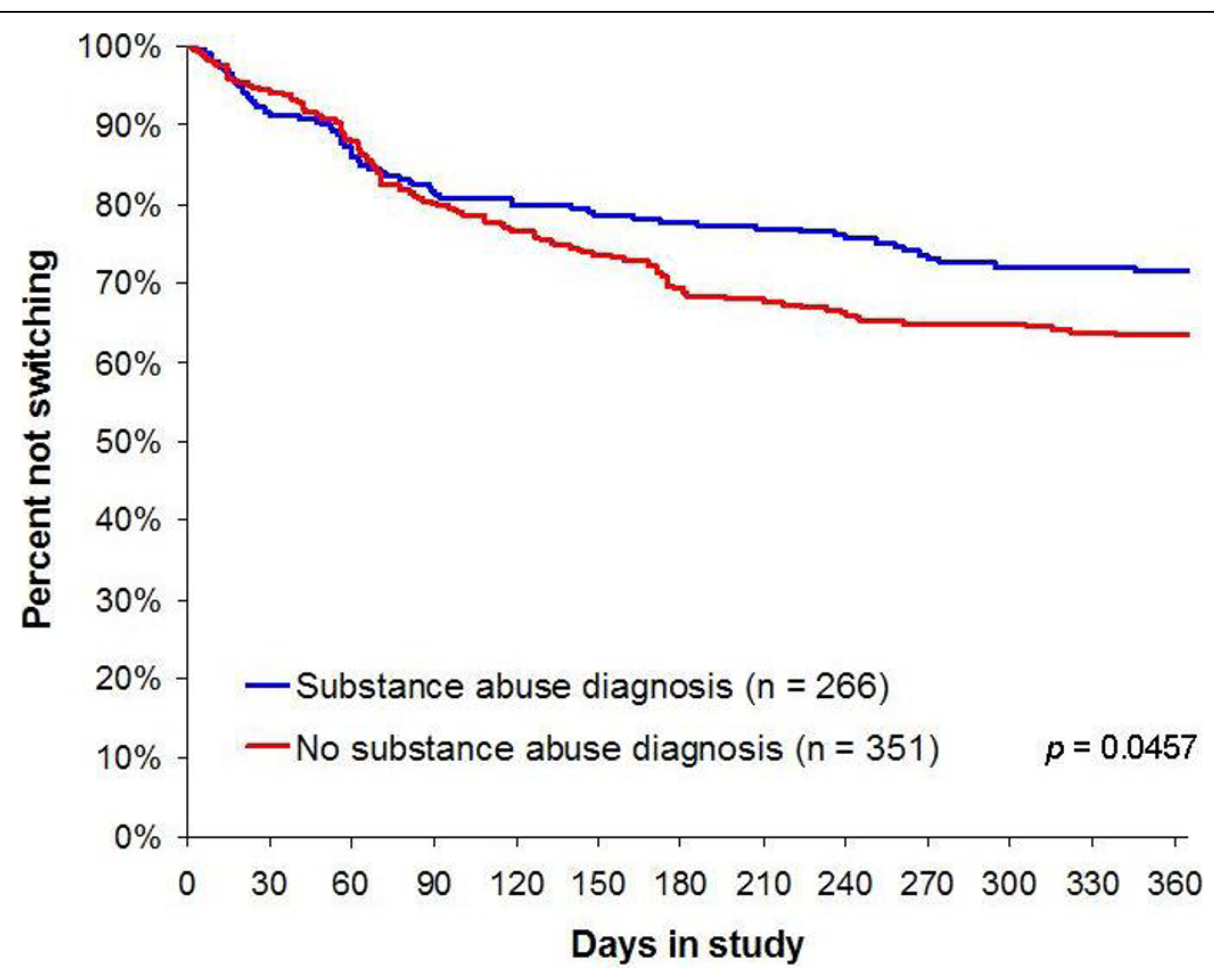

Figure 2 Current or Previous Substance Abuse Diagnosis

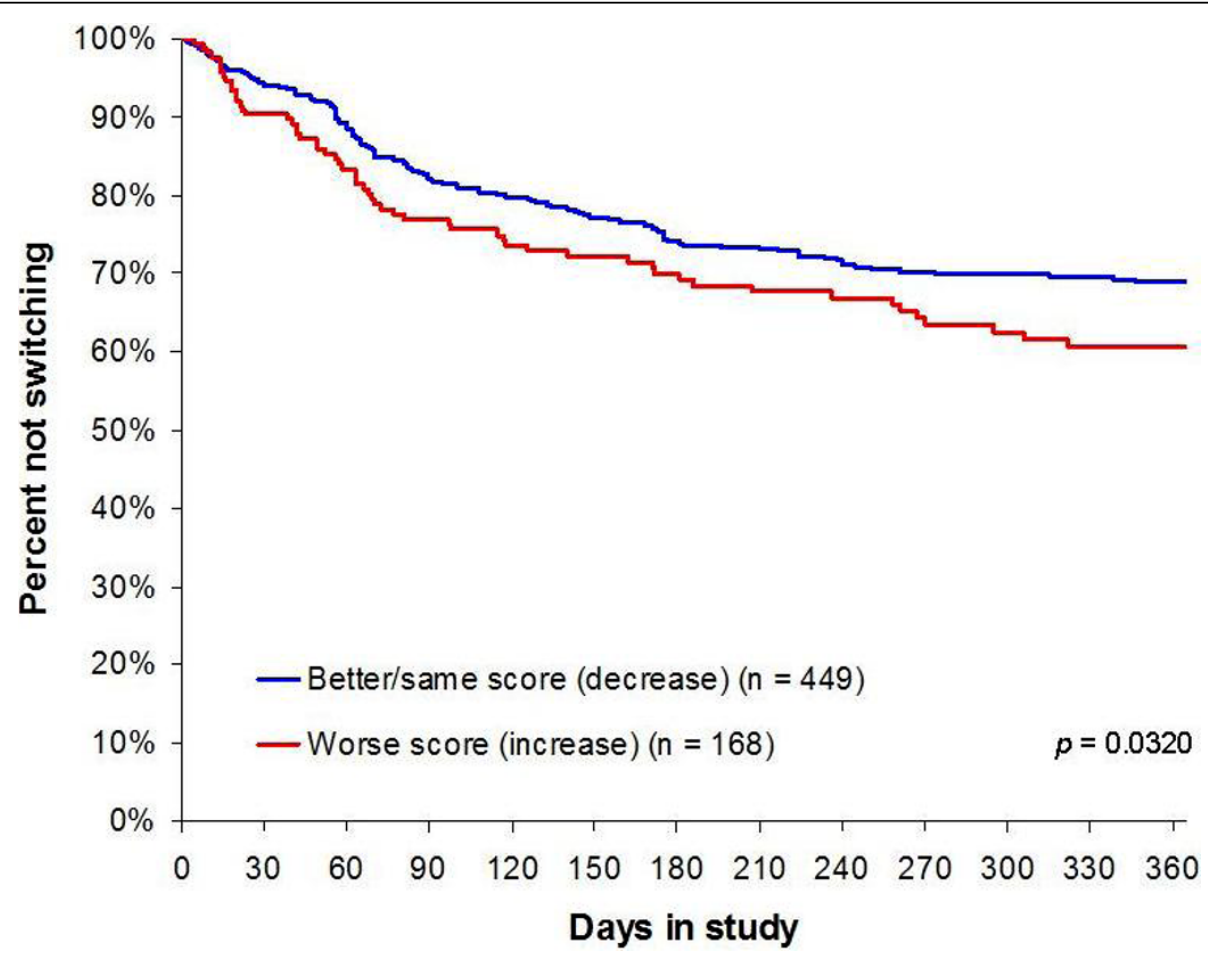

Figure 3 PANSS Davis Anxiety/Depression Change From Baseline to 2 Weeks. 


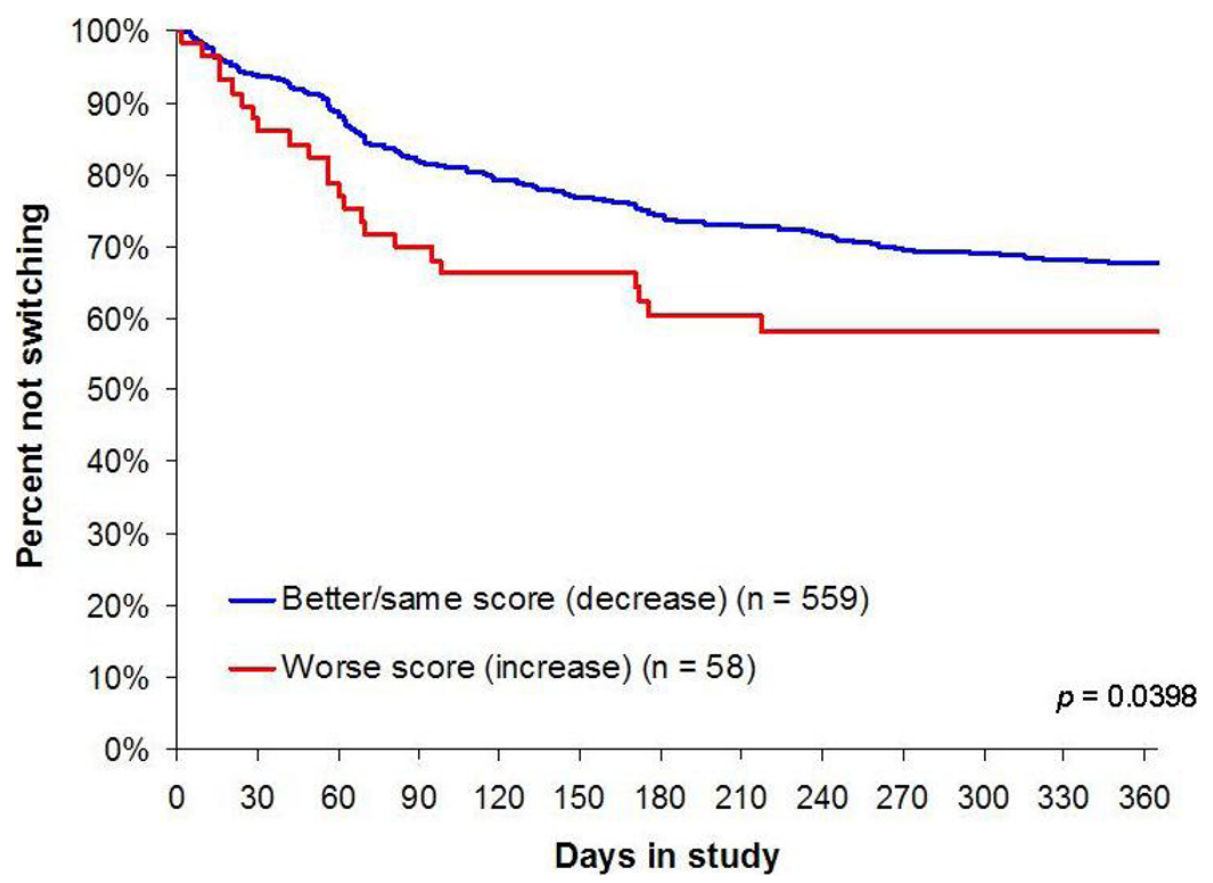

Figure 4 Barnes Akathisia Objective Score Change From Baseline to 2 Weeks.

significantly predicted switching of medication and earlier switching. Patients who did not use antipsychotic medications in the year preceding the study were more likely to switch or require an earlier switch, likely reflecting prior nonadherence with antipsychotic medications in these chronically and moderately ill patients. Previous research by our group demonstrated that patients with schizophrenia who were enrolled in a large three-year prospective observational, noninterventional study (USSCAP) and were nonadherent to antipsychotic medication regimens in the six months before enrollment were over four times more likely to subsequently discontinue such treatment for any cause [36].

In the present study, women with schizophrenia were also significantly more likely than their male counterparts to switch medications or evidence an earlier medication switch. This finding, however, may reflect ascertainment bias, in that women with schizophrenia may, in general, use mental health services more frequently than their male counterparts [37]. Increased service use (e.g., physician visits) might in turn be associated with a higher likelihood of detecting a suboptimal treatment response or a treatment-emergent adverse event culminating in medication switching [38].

We also found that patients diagnosed with a substance use disorder were less likely to switch antipsychotic medications and less likely to switch earlier. This predictor seemed, at first, somewhat at odds with previous research, especially with findings of a large, prospective, observational study in which patients with schizophrenia with concurrent substance abuse problems were more likely to discontinue antipsychotic regimens for any cause [14]. However, all-cause medication discontinuation is composed of medication switching and study discontinuation, two components on which patient subgroups seem to differ. The importance of separating switchers from study discontinuers was illustrated in a previous analysis of the current study dataset (HGGD). In that post-hoc analysis [14], patients with substance use were significantly more likely to discontinue their medication and to withdraw from the study rather than switch medications. Furthermore, the finding that patients with substance use disorders were less likely to switch antipsychotic medications and less likely to switch earlier might also represent the confounding by gender, because switchers were more likely to be women and substance use is less prevalent among women than men [37].

Arguably one of the most important findings of the current study is that affective symptoms and, specifically, depressive and anxiety symptoms (pre-existing depression and worsening of depression and anxiety symptoms during the first two weeks of treatment), appear to be robust predictors of subsequent switching or earlier switching of medication. Current findings are consistent with previous research demonstrating that depressive symptoms are associated with a significantly higher propensity to discontinue treatment for any 
cause [39-41]. The study by Kinon and colleagues [40] investigated this aspect in some detail, with a post-hoc analysis of pooled data from four antipsychotic trials for the treatment of schizophrenia $(n=1,627)$. That study showed that patients with a 4-point improvement in PANSS depression/anxiety subscore were significantly less likely to discontinue treatment, and an early response in depressive/anxiety symptoms was associated with a $50 \%$ greater likelihood of study completion. These, along with the current findings, emphasize the prognostic value of affective symptoms, especially depression and anxiety, in the treatment of patients with schizophrenia.

The current findings also highlight the importance of early worsening akathisia as a predictor of medication switching. These results are consistent with prior research showing that akathisia is bothersome and distressing to patients [42-44] and is associated with medication nonadherence $[45,46]$.

It is of interest that no association was found between medication switching and baseline body weight, BMI, or treatment-emergent body weight in the first two weeks of treatment. It is possible that health concerns about treatment-emergent weight gain were not yet pronounced during the study period (through 2002), thus did not lead to medication switching by the clinicians. It is also possible that clinicians have recognized the association between therapeutic response and greater treatment-emergent weight gain [47-50] and opted, after risk-to-benefit assessment, not to switch most of these patients' medications. These hypotheses are speculative, as further research is needed to help clarify reasons for medication continuation and reasons for medication discontinuation from the patients' and clinicians' perspectives.

The CATIE schizophrenia study $[2,4,6,7]$ found that individuals who had "continuation" (randomized to the same antipsychotic they had received prior to study entry) had significantly longer times to all-cause discontinuation. Indeed, when this variable was tested in our study, it was a significant predictor $(\mathrm{p}<.001)$ of switching. When, as a sensitivity analysis, the final predictive model was re-fit to only the set of patients $(n=442)$ who did not have continuation, the results showed hazard ratios which were directionally consistent with the original predictive model.

Study findings need to be evaluated in light of its limitations. First is the study's post-hoc nature, suggesting the need for additional longitudinal research to confirm the findings in an a priori manner. Second, patients enrolled in this study were primarily chronically ill outpatients with schizophrenia with about 20 years of illness duration, who agreed to participate in a randomized study; therefore, our findings may not be applicable to first-episode patients to inpatients, or to patients treated in a usual care setting. In addition, this study was conducted during a timeframe when secondgeneration antipsychotics were fairly new to the market, so it is not clear how changes in the standards of treatment over time may have impacted the switching decision-making process. Another limitation is the timeto-event survival analysis: whether "censored" (discontinued from the study) subjects would have soon switched medication cannot be determined since they were not followed up after dropping out of the study. This limitation may help explain the finding that a lack of substance use disorder was predictive of switching, because substance users are prone to study discontinuation rather than to switch medications [14,51]. Traditional survival analyses assume that censoring is independent of the outcome event (in this case, switching), an assumption that is not likely to be fully satisfied. Next, although a relatively wide range of potential predictors of switching was examined, the list was not exhaustive. The study lacked data on changes in metabolic parameters (besides body weight) and prolactin levels, and these changes may lead some clinicians to switch medications. Consequently, further research is needed to incorporate such important safety measures when assessing predictors of switching. In addition, the most frequent reason for switching was "patient's decision," thus limiting the ability to discern what may have triggered the switch for a substantial proportion of the patients. Finally, but most importantly, this study focused on switchers and not on patients who discontinued the study early, although information about discontinuers is also of interest and clinical importance. Therefore, further research is needed to compare baseline and early treatment characteristics of switchers and discontinuers and assess whether predictors of switching differ from predictors of medication discontinuation in the treatment of patients with schizophrenia. Despite its limitations, this study has a number of strengths. In addition to conducting survival analyses to assess time to switching, the study used liberal eligibility criteria and was conducted in naturalistic settings, which may enhance the ability to generalize the current findings to the wider U.S. outpatient schizophrenia patient population. Another strength of the present study is the broad spectrum of patient-level variables examined as potential predictors and the use of "early on-treatment" variables to assess the predictive value of early changes in patients' status to reflect the medication's early efficacy, tolerability, and safety.

\section{Conclusions}

In conclusion, switching antipsychotic medications is common in the outpatient management of schizophrenia 
and can be considered a surrogate for treatment failure in many patients. Early suboptimal treatment outcomes in terms of efficacy (worsening of depressive/anxiety symptoms) and tolerability (worsening of akathisia) significantly predict switching or an earlier time to switch. Patient characteristics predictive of switching earlier included female gender, a history of depression, and the lack of recent use of antipsychotics. Further longitudinal studies are needed to evaluate and replicate these findings.

\section{Acknowledgements}

This study was funded by Eli Lilly and Company, which had a role in study design, data analysis, preparation and revision of the manuscript, and the decision to publish findings. Principal Investigators contributing data in this multicenter trial (HGGD) were Denis Mee-Lee MD, Honolulu, Hi; Michael Brody MD, Washington, DC; Christopher Kelsey MD and Gregory Bishop MD, San Diego, CA; Lauren Marangell MD, Houston, TX; Frances Frankenburg MD, Belmont, MA; Roger Sommi PharmD, Kansas City, MO; Ralph Aquila MD and Peter Weiden MD, New York, NY; Dennis Dyck PhD, Spokane, WA; Rohan Ganguli MD, Pittsburgh, PA; Rakesh Ranjan MD; Nagui Achamallah MD and Bruce Anderson MD, Vallejo, CA; Terry Bellnier RPh, Rochester, NY; John S. Carman MD, Smyrna, GA; Andrew J. Cutler MD, Winter Park, FL; Hisham Hafez MD, Nashua, NH; Raymond Johnson MD, Ft. Myers, FL; Ronald Landbloom MD, St. Paul, MN; Theo Manschreck MD, Fall River, MA; Edmond Pi MD, Los Angeles, CA; Michael Stevens MD, Salt Lake City, UT; and Richard Josiassen PhD, Norristown, PA. Appreciation is also expressed to Rete Biomedical Communications Corp. (Ridgewood, NJ) for assistance in manuscript preparation.

\section{Authors' contributions}

All authors participated in the study conduct and design. AWN, DEF, and HA-S provided oversight of the study design. AWN was responsible for the acquisition of the data. All authors participated in the interpretation of the data. AWN and HA-S prepared the manuscript with editorial assistance from Rete Biomedical Communications Corp. and revisions by all authors. All authors read and approved the final manuscript.

\section{Competing interests}

The authors are full-time employees of and minor shareholders of Eli Lilly and Company.

Received: 4 March 2010 Accepted: 28 September 2010

Published: 28 September 2010

\section{References}

1. Hamer S, Haddad PM: Adverse effects of antipsychotics as outcome measures. Br J Psychiatry Suppl 2007, 50:s64-s70.

2. Lieberman JA, Stroup TS, MCEvoy JP, Swartz MS, Rosenheck RA, Perkins DO, Keefe RS, Davis SM, Davis CE, Lebowitz BD, Severe J, Hsiao JK, Clinical Antipsychotic Trials of Intervention Effectiveness (CATIE) Investigators: Effectiveness of antipsychotic drugs in patients with chronic schizophrenia. N Engl J Med 2005, 353(12):1209-1223.

3. Dossenbach MR, Kratky P, Schneidman M, Grundy SL, Metcalfe S, Tollefson GD, Belmaker RH: Evidence for the effectiveness of olanzapine among patients nonresponsive and/or intolerant to risperidone. J Clin Psychiatry 2001, 62(Suppl 2):28-34.

4. McEvoy JP, Lieberman JA, Stroup TS, Davis SM, Meltzer HY, Rosenheck RA, Swartz MS, Perkins DO, Keefe RS, Severe J, Hsiao JK, CATIE Investigators: Effectiveness of clozapine versus olanzapine, quetiapine, and risperidone in patients with chronic schizophrenia who did not respond to prior atypical antipsychotic treatment. Am J Psychiatry 2006, 163(4):600-610.

5. Park S, Ross-Degnan D, Adams AS, Sabin J, Kanavos P, Soumerai SB: Effect of switching antipsychotics on antiparkinsonian medication use in schizophrenia: population-based study. Br J Psychiatry 2005, 187:137-142.

6. Stroup TS, Lieberman JA, McEvoy JP, Swartz MS, Davis SM, Rosenheck RA, Perkins DO, Keefe RS, Davis CE, Severe J, Hsiao JK, CATIE Investigators:
Effectiveness of olanzapine, quetiapine, risperidone, and ziprasidone in patients with chronic schizophrenia following discontinuation of a previous atypical antipsychotic. Am J Psychiatry 2006, 163(4):611-622.

7. Stroup TS, Lieberman JA, MCEvoy JP, Swartz MS, Davis SM, Capuano GA, Rosenheck RA, Keefe RS, Miller AL, Belz I, Hsiao JK, CATIE Investigators: Effectiveness of olanzapine, quetiapine, and risperidone in patients with chronic schizophrenia after discontinuing perphenazine: a CATIE study. Am J Psychiatry 2007, 164(3):415-427.

8. Weiden PJ, Simpson GM, Potkin SG, O'Sullivan RL: Effectiveness of switching to ziprasidone for stable but symptomatic outpatients with schizophrenia. J Clin Psychiatry 2003, 64(5):580-588.

9. Weiden PJ: Switching antipsychotics: an updated review with a focus on quetiapine. J Psychopharmacol 2006, 20(1):104-118.

10. Weiden PJ: Switching antipsychotics as a treatment strategy for antispsychotic-induced weight gain and dyslipidemia. J Clin Psychiatry 2007, 68(Suppl 4):34-39.

11. Liu-Seifert H, Adams DH, Kinon BJ: Discontinuation of treatment of schizophrenia patients is driven by poor symptom response: a pooled post-hoc analysis of four atypical antipsychotic drugs. BMC Med 2005, 3:21.

12. Sernyak MJ, Leslie $D$, Rosenheck R: Predictors of antipsychotic medication change. J Behav Health Serv Res 2005, 32(1):85-94.

13. Weinmann S, Janssen B, Gaebel W: Switching antipsychotics in inpatient schizophrenia care: predictors and outcomes. J Clin Psychiatry 2004, 65(8):1099-1105

14. Smelson DA, Tunis TS, Nyhuis AW, Faries DE, Kinon BJ, Ascher-Svanum H: Antipsychotic treatment discontinuation among individuals with schizophrenia and co-occurring substance use. J Clin Psychopharmacol 2006, 26(6):666-667.

15. Faries DE, Ascher-Svanum H, Nyhuis AW, Kinon BJ: Clinical and economic ramifications of switching of antipsychotics in the treatment of schizophrenia. BMC Psychiatry 2009, 9:54.

16. Tunis SR, Stryer DB, Clancy CM: Practical clinical trials: increasing the value of clinical research for decision making in clinical and health policy. $J$ Am Med Assoc 2003, 290(12):1624-1632.

17. Tunis SL, Faries DE, Nyhuis AW, Kinon BJ, Ascher-Svanum H, Aquila R: Costeffectiveness of olanzapine as first-line treatment for schizophrenia: results from a randomized, open-label, 1-year trial. Value Health 2006, 9(2):77-89.

18. Tunis SL, Faries DE, Stensland MD, Hay DP, Kinon BJ: An examination of factors affecting persistence with initial antipsychotic treatment in patients with schizophrenia. Curr Med Res Opin 2007, 23(1):97-104.

19. Overall JE, Gorham DR: The brief psychiatric rating scale. Psychol Rep 1962, 10:799-812.

20. Agid O, Kapur S, Arenovich T, Zipursky RB: Delayed-onset hypothesis of antipsychotic action: a hypothesis tested and rejected. Arch Gen Psychiatry 2003, 60(12):1228-1235.

21. Ascher-Svanum $H$, Nyhuis AW, Faries DE, Kinon BJ, Baker RW, Shekhar A: Clinical, functional, and economic ramifications of early nonresponse to antipsychotics in the naturalistic treatment of schizophrenia. Schizophr Bull 2008, 34(6):1163-1171.

22. Correll CU, Malhotra AK, Kaushik S, McMeniman M, Kane JM: Early prediction of antipsychotic response in schizophrenia. Am J Psychiatry 2003, 160(11):2063-2065.

23. Leucht S, Busch R, Hamann J, Kissling W, Kane JM: Early-onset hypothesis of antipsychotic drug action: a hypothesis tested, confirmed and extended. Biol Psychiatry 2005, 57(12):1543-1549.

24. Leucht S, Busch R, Kissling W, Kane JM: Early prediction of antipsychotic nonresponse among patients with schizophrenia. J Clin Psychiatry 2007, 68(3):352-360.

25. Kay SR, Fiszbein A, Opler LA: The positive and negative syndrome scale (PANSS) for schizophrenia. Schizophr Bull 1987, 13(2):261-276.

26. Davis JM, Chen N: The effects of olanzapine on the 5 dimensions of schizophrenia derived by factor analysis: combined results of the North American and international trials. J Clin Psychiatry 2001, 62(10):757-771.

27. Lehman AF: A quality of life interview for the chronically mentally ill. Eval Program Plann 1988, 11(4):51-62.

28. Ware JE Jr, Sherbourne CD: The MOS 36-item short form health survey (SF-36). I. Conceptual framework and item selection. Med Care 1992, 30(6):473-483.

29. Endicott J, Spitzer RL, Fleiss JL, Cohen J: The global assessment scale. A procedure for measuring overall severity of psychiatric disturbance. Arch Gen Psychiatry 1976, 33(6):766-771. 
30. Barnes TR: A rating scale for drug-induced akathisia. Br J Psychiatry 1989 154:672-676.

31. Simpson $G M$, Angus JW: A rating scale for extrapyramidal side effects. Acta Psychiatr Scand Suppl 1970, 212:11-19.

32. Kraemer HC, Wilson GT, Fairburn CG, Agras WS: Mediators and moderators of treatment effects in randomized clinical trials. Arch Gen Psychiatry 2002, 59(10):877-883.

33. Almond $S$, Knapp M, Francois C, Toumi M, Brugha T: Relapse in schizophrenia: costs, clinical outcomes and quality of life. $\mathrm{Br} J$ Psychiatry 2004, 184:346-351.

34. Leslie DL, Rosenheck RA: From conventional to atypical antipsychotics and back: dynamic processes in the diffusion of new medications. Am J Psychiatry 2002, 159(9):1534-1540.

35. Weiden PJ, Olfson M: Cost of relapse in schizophrenia. Schizophr Bull 1995, 21(3):419-429.

36. Ascher-Svanum H, Faries DE, Zhu B, Ernst FR, Swartz MS, Swanson JW: Medication adherence and long-term functional outcomes in the treatment of schizophrenia in usual care. J Clin Psychiatry 2006, 67(3):453-460.

37. Lindamer LA, Bailey A, Hawthorne W, Folsom DP, Gilmer TP, Garcia P, Hough RL, Jeste DV: Gender differences in characteristics and service use of public mental health patients with schizophrenia. Psychiatr Serv 2003, 54(10):1407-1409.

38. Svarstad BL, Shireman $\mathrm{TI}$, Sweeney JK: Using drug claims data to assess the relationship of medication adherence with hospitalization and costs. Psychiatr Serv 2001, 52(6):805-811.

39. Ascher-Svanum H, Zhu B, Faries D, Lacro JP, Dolder CR: A prospective study of risk factors for nonadherence with antipsychotic medication in the treatment of schizophrenia. J Clin Psychiatry 2006, 67(7):1114-1123.

40. Kinon BJ, Ascher-Svanum $H$, Adams DH, Chen $L$ : The temporal relationship between symptom change and treatment discontinuation in a pooled analysis of 4 schizophrenia trials. J Clin Psychopharmacol 2008, 28(5):544-549.

41. Rabinowitz J, Davidov O: The association of dropout and outcome in trials of antipsychotic medication and its implications for dealing with missing data. Schizophr Bull 2008, 34(2):286-291.

42. Drake RE, Ehrlich J: Suicide attempts associated with akathisia. Am J Psychiatry 1985, 142(4):499-501.

43. Hansen L: A critical review of akathisia, and its possible association with suicidal behaviour. Hum Psychopharmacol 2001, 16(7):495-505.

44. Margolese HC, Chouinard G, Larach WW, Beauclair L: Relationship between antipsychotic-induced akathisia and tardive dyskinesia and suicidality in schizophrenia: impact of clozapine and olanzapine. Acta Psychiatr Belg 2001, 101:128-144

45. Fleischhacker WW, Meise U, Günther V, Kurz M: Compliance with antipsychotic drug treatment: influence of side effects. Acta Psychiatr Scand 1994, 382:11-15.

46. Kapur S, Remington G: Atypical antipsychotics. BMJ 2000, 321(7273):1360-1361.

47. Ascher-Svanum H, Stensland MD, Kinon BJ, Tollefson GD: Weight gain as a prognostic indicator of therapeutic improvement during acute treatment of schizophrenia with placebo or active antipsychotic. J Psychopharmacol 2005, 19(6 Suppl):110-117.

48. Ascher-Svanum H, Zhu B, Faries D, Landbloom R, Swartz M, Swanson J: Time to discontinuation of atypical versus typical antipsychotics in the naturalistic treatment of schizophrenia. BMC Psychiatry 2006, 6:8.

49. Czobor P, Volavka J, Sheitman B, Lindenmayer JP, Citrome L, McEvoy J, Cooper TB, Chakos M, Lieberman JA: Antipsychotic-induced weight gain and therapeutic response: a differential association. $J$ Clin Psychopharmacol 2002, 22(3):244-251.
50. Meltzer HY, Perry E, Jayathilake K: Clozapine-induced weight gain predicts improvement in psychopathology. Schizophr Res 2003, 59(1):19-27.

51. Miller R, Ream G, McCormack J, Gunduz-Bruce H, Sevy S, Robinson D: A prospective study of cannabis use as a risk factor for non-adherence and treatment dropout in first-episode schizophrenia. Schizophr Res 2009, 113(2-3):138-144.

\section{Pre-publication history}

The pre-publication history for this paper can be accessed here: http://www.biomedcentral.com/1471-244X/10/75/prepub

doi:10.1186/1471-244X-10-75

Cite this article as: Nyhuis et al:: Predictors of switching antipsychotic medications in the treatment of schizophrenia. BMC Psychiatry 2010 10:75.

\section{Submit your next manuscript to BioMed Central and take full advantage of:}

- Convenient online submission

- Thorough peer review

- No space constraints or color figure charges

- Immediate publication on acceptance

- Inclusion in PubMed, CAS, Scopus and Google Scholar

- Research which is freely available for redistribution

Submit your manuscript at www.biomedcentral.com/submit
Ciomed Central 